\title{
ANALISIS PERAN LEMBAGA TERHADAP PROGRM KRPL (KAWASAN RUMAH PANGAN LESTARI) DI DESA PUCANGSARI KECAMATAN PURWODADI KABUPATEN PASURUAN
}

\author{
M. Subadar *) \\ *) Jurusan Agribisnis Fakultas Pertanian Universitas Yudharta Pasuruan \\ Subadar_Muhammad@yahoo.com
}

\begin{abstract}
ABSTRAK
Tujuan penelitian untuk mengetahui peran lembaga terhadap program KRPL yang ada di desa pucangsari kecamatan purwodadi kabupaten pasuruan, terdapat 4 lembaga yang menggerakkan program KRPL yaitu Penyuluh Pertanian, KWT, PKK, dan TPD. Sedangkan sampel yang digunakan dalam penelitian ini sebanyak 84 orang pengumpulan data berupa data primer dan skunder, proses pemerolehan data menggunakan studi lapangan dengan instrumen penelitian berupa kuisioner, wawancara, dan studi pustaka. Analisis data dalam penelitian ini dengan menggunakan uji regresi logit. Hasil dari odds ratio menunjukkan bahwa variabel KWT memilki peran terhadap KRPL sebesar 18\%, variabel PKK sebesar 16\%, variabel TPD sebesar $14 \%$, dan variabel Penyuluh Pertanian sebesar 17\%. Diantara semua lembaga tersebut masingmasing memiliki peran yang signifikan terhadap program KRPL dan lembaga yang memiliki peran lembaga paling besar adalah lembaga KWT.
\end{abstract}

Kata Kunci: Peran, Lembaga, KRPL

\section{PENDAHULUAN}

Peningkatan pertumbuhan produksi pangan kiranya akan sulit dilakukan karena tidak semua negara berkembang memiliki ketersediaan lahan yang layak atau subur untuk mengembangkan pertanian dan produksi pangan. Penguasaan teknologi yang kurang sepadan akan menghambat upaya untuk mengubah lahan yang kurang layak atau tidak subur menjadi layak untuk pengembangan pertanian.

Pemenuhan kebutuhan pangan dengan memperhatikan sumberdaya lokal ini akan memberikan dampak yang positif bagi rumah tangga dan lingkungannya dengan pemenfaatan penggunaan sumberdaya lokal, banyak keuntungan yang dapat diraih yaitu keuntungan secara ekologis, ekonomis, sosial, dan keuntungan kesehatan bagi rumah tangga, dalam program KRPL ini tiap rumah tangga diwajibkan memiliki sebidang tanaman pertanian holtikultura, peternakan dan perikanan.

Penerapan RPL ini dikelompokkan berdasar luasan lahan yang dimilki mulai dari strata 1 sampai strata 3, untuk mencukupi kebutuhan makanan sehari-hari dalam keluarganya, untuk melaksanakan program disersivikasi pangan ini di butuhkan keterlibatan masyarakat dalam mensukseskan keberhasilan dimana masyarakat adalah pemeran utama untuk menjalankan program KRPL.

Di pedesaan terdapat berbagai macam kelembagaan, seperti yang dikemukakan oleh Djatmiko dan Dwiatmoko (1993) bahwa di desa terdapat berbagai 
macam kelompok swadaya. Pertama, adalah kelompok yang secara spontan tumbuh dari kemauan masyarakat sendiri seperti kelompok/pranata sambatan. Kedua, adalah kelompok yang tumbuh dari dorongan individu dalam masyarakat sebagai akumulasi kepentingan masyarakat seperti kelompok hajatan, arisan kelompok lingkungan RT dan lainnya. Ketiga, adalah kelompok yang ada karena bentukan dari atas (pemerintah) seperti PKK, LMD, LKMD, 2) karang taruna dan lainnya.

Desa Pucangsari sebagai salah satu 4) TPD (X4)

daerah yang telah menerima dan melaksanakan pengembangan program KRPL sejak dari tahun 2004 sampai sekarang yang di koordinatori oleh KWT Mayangsari dan dibantu oleh lembaga desa yang lainnya, banyak hal yang perlu di evaluasi terutama aspek kelembagaan. Walaupun program KRPL telah bertahun-tahun berjalan, evaluasi tetap diperlukan sebagai bahan atau referensi bagi program-program pemberdayaan masyarakat.

Permasalahan dalam penelitian ini sejuah mana peran KWT dalam menjalankan progam KRPL. Bagaimana peran lembaga desa dalam mendukung program KRPL. Tujuan peneelitian mengetahui peran KWT dalam menjalankan program KRPL dan mengetahui peran lembaga desa dalam mendukung program KRPL.
3) Lembaga PKK (X3)

\section{METODE PENELITIAN}

Jumlah Responden dalam penelitian ini meliputi lembaga yang ikut serta dalam mengembangkan program KRPL yaitu KWT, PKK, TPD dan, Penyuluh dengan jumlah 84 orang.

Dalam penelitian ini ada dua jenis variabel yaitu variable bebas (independen variabel) meliputi :

) Penyuluh Pertanian (X1)

KWT Mayang Sari (X2)

Dan variabel terikat (dependent variabel) adalah kelembagaan yang memiliki kontribusi terhadap program KRPL. Dikarenakan dalam penelitian ini variabel terikat (Y) merupakan Dummy variabel maka ditentukan indikator variabel terikat adalah sebagai berikut:

1. Diterima, seorang anggota KRPL merasa terfasilitasi oleh lembaga yang memiliki peran dan kontribusi terhadap program KRPL.

2. Tidak diterima, seorang anggota KRPL akan merasa tidak menerima bila lembaga ternyata tidak dapat menjalankan program KRPL.

Analisi data yang digunakan dalam penelitian ini adalah analisis regresi logit. Dan untuk pengujian hipotesis statistik dilakukan uji ketetapan model, uji signifikasi seluruh model (simultan) dan uji signifikasi setiap parameter (parsial).

I. 


\section{HASIL DAN PEMBAHASAN}

Hasil pada pengolahan data primer diperoleh sebagaimana dalam tabel jika dimasukkan dalam persamaan sebagai berikut:

$\ln \left[\frac{P}{1-p}\right]=-21,283+0,606+0,490+0,392+$ 0,547

\section{a. Variabel KWT (X1)}

Hasil analisis dari regresi logit menunjukkan bahwa pada taraf signifikan 5\%, variabel KWT memiliki indeks probabilitas sebesar 0,001 yang lebih kecil dari $0,05(0,001<0,05)$.

Hal ini menjelaskan bahwa variabe KWT memiliki pengaruh peran yang signifikan terhadap program KRPL yang ada didesa pucangsari kecamatan purwodadi kabupaten pasuruan, dan pada analisis odds ratio variabel KWT memiliki nilai (exp. $\mathrm{B}=$ 1,833) yang mengartikan bahwa jika variabel KWT (X1) ditingkatkan sebesar 1,833 maka variabel KWT (X1) akan memiliki peningkatan peran lembaga terhadap program KRPL yang ada di desa pucangsari kecamatn purwodadi kabupaten pasuruan sebesar 1,8\%.

Hal ini menjelaskan KWT memiliki peran yang lebih besar untuk menjalankan kegiatan yang ada pada program KRPL, lembaga KWT merupakan lembaga yang mengkoordinir dari tiap lemabag desa yang ikut serta untuk menjalankan kegiatan yang ada di KRPL.
Keberadaan wanita sangat dibutuhkan untuk ikut berpartisipasi aktif, KWT Sebagai kelompok wanita tani memiliki potensi yang besar untuk memberikan kontribusi dalam pembangunan pertanian yang mana dalam pembangunan pedesaan tidak bisa lepas dari pembangunan pertanian. Wanita tani dalam usahatani banyak berperan mulai dari mengadakan kegiatan pertemuan rutin di KRPL dengan pembahasan dan pemecahan maslah yang timbul pada anggota yang menjalankan program KRPL, KWT juga sebagai kelompok yang menyediakan saprodi KRPL.

\section{b. Variabel PKK (X2)}

Hasil analisis dari regresi logit menunjukkan bahwa pada taraf signifikan 5\%, variabel PKK memiliki indeks probabilitas sebesar 0,008 yang lebih kecil dari $0,05(0,008<0,05)$. Hal ini menjelaskan bahwa variabel PKK memiliki pengaruh peran yang signifikan terhadap program KRPL yang ada didesa pucangsari kecamatan purwodadi kabupaten pasuruan, dan pada analisis odds ratio variabel PKK memiliki nilai (exp. $\mathrm{B}=1,632$ ) yang mengartikan bahwa jika variabel PKK (X2) ditingkatkan sebesar 1,632 maka variabel PKK (X2) akan memiliki peningkatan peran lembaga terhadap program KRPL yang ada di desa pucangsari kecamatn purwodadi kabupaten pasuruan sebesar $1,6 \%$.

Dari hasil penelitian bahwa lembaga PKK memiliki pengaruh yang signifikan 
terhadap program KRPL. Hal ini d. Penyuluh Pertanian (X4)

menjelaskan lembaga PKK memilki andil dalam menjalankan program KRPL. Dapat kita ketahui PKK merupakan perkumpulan para ibu dan para remaja puteri atau kaum wanita. Memang pada umumnya kegiatan PKK ini boleh dikatakan kegiatan para kaum wanita.

c. TPD (X3)

Hasil analisis dari regresi logit menunjukkan bahwa pada taraf signifikan $5 \%$, variabel lembaga TPD memiliki indeks probabilitas sebesar 0,043 yang lebih kecil dari $0,05(0,043<0,05)$. Hal ini menjelaskan bahwa variabel TPD memiliki pengaruh peran yang signifikan terhadap program KRPL yang ada didesa pucangsari kecamatan purwodadi kabupaten pasuruan, dan pada analisis odds ratio variabel TPD memiliki nilai (exp. $\mathrm{B}=1,480$ ) yang mengartikan bahwa jika variabel TPD (X3) ditingkatkan sebesar 1,480 maka variabel TPD (X3) akan memiliki peningkatan peran lembaga terhadap program KRPL yang ada di desa pucangsari kecamatn purwodadi kabupaten pasuruan sebesar 1,5\%.

Sebagai lembaga yang ditunjuk oleh pemerintahan desa lembaga TPD memiliki peran terhadap program KRPL yaitu dengan memfasilitasi segala urusan yang berkaitan dengan administrasi dan sebagai partner pemerintah dalam mengembangkan potensi sumberdaya yang ada diwilayah KRPL.
Hasil analisis dari regresi logit menunjukkan bahwa pada taraf signifikan $5 \%$, variabel lembaga Penyuluh Pertanian memiliki indeks probabilitas sebesar 0,007 yang lebih kecil dari $0,05(0,007<0,05)$. Hal ini menjelaskan bahwa variabel Penyuluh Pertanian memiliki pengaruh peran yang signifikan terhadap program KRPL yang ada didesa pucangsari kecamatan purwodadi kabupaten pasuruan, dan pada analisis odds ratio variabel Penyuluh Pertanian memiliki nilai (exp. $\mathrm{B}=1,727$ ) yang mengartikan bahwa jika variabel Penyuluh Pertanian (X4) ditingkatkan sebesar 1,727 maka variabel Penyuluh Pertanian (X4) akan memiliki peningkatan peran lembaga terhadap program KRPL yang ada di desa pucangsari kecamatn purwodadi kabupaten pasuruan sebesar 1,7\% .

Dari hasil penelitian lembaga Penyuluh pertanian memiliki pengaruh yang signifikan terhadap program KRPL. Hal ini menjelaskan bahwa lembaga Penyuluh memilki andil dalam menjalankan program KRPL. 
Tabel 1. Analisis regresi logit

\begin{tabular}{|c|c|c|c|c|c|}
\hline Variabel & B & Wald & Probabilitas & Exp.B & Keterangan \\
\hline Konstanta & $-21,283$ & 16,912 & 0,000 & 0,000 & \\
\hline KWT (X1) & 0,606 & 10,652 & 0,001 & 1,833 & Signifikan \\
\hline PKK (X2) & 0,490 & 7,052 & 0,008 & 1,632 & Signifikan \\
\hline TPD (X3) & 0,392 & 4,103 & 0,043 & 1,480 & Signifikan \\
\hline Penyuluh (X4) & 0,547 & 7,213 & 0,007 & 1,727 & Signifikan \\
\hline
\end{tabular}

Sumber: Data Primer (diolah)

\section{KESIMPULAN}

Diantara lembaga yang menjalankan program KRPL lembaga KWT sebagai variabel (X1) memiliki peran yang lebih besar dibandingkan dengan lembaga desa yang lainnya yaitu sebesar (Exp. $\mathrm{B}=1,833$ ) sesuai dengan perannya lembaga KWT menjalankan program KRPL dengan mengadakan kegiatan rutin setiap bulan, penyediaan bibit, dan penyediaan pupuk. Lembaga desa PKK (X2), TPD (X3), dan Penyuluh Pertanian (X4) sesuai dengan perannya masing-masing juga membantu KWT dalam menjalankan program KRPL masing-masing lembaga memiliki nilai PKK (Exp. $\mathrm{B}=1,632)$, TPD (Exp. $\mathrm{B}=1,480)$, Penyuluh Pertanian (Exp. B = 1,727).

\section{DAFTAR PUSTAKA}

Arikunto, Suharsimi. 2002. Prosedur Penelitia suatu Pendekatan Praktek. Edisi lima. Yogyakarta : Rineka Cipta Badan Litbang Pertanian. 2012.

Blau, Peter M. \& W. Richard Scott. 1996. Formal Organizations: A Comparativ Approach. San Francisco: Chandler Publishing Co
Djiwandi, 1994. Pengaruh Dinamika Kelompok Tani Terhadap Kecepatan Adopsi Teknologi Usahatani. Jakarta.

Eaton, Joseph W. (ed). 2000 Pembangunan Lembaga dan Pembangunan Nasional: Dari Konsep Kegiatan Aplikasi. TerjemahanCetakan Pertama. Jakarta: Universitas Indonesi Press.Etzioni,

Amitai. 1995. Organisasi-Organisasi Modern. Terjemahan. Jakarta: PT. Gramedia Pustaka Utama.

Hendropuspito, O.C. 1999. Sosiologi Sistematik. Jakarta: Penerbit Kanisius.

Indrawijaya, Adam I. 2000. Perilaku Organisasi. Bandung: Sinar Baru Algesindo.

Lubis, S.B. Hari \& Martani Huseini. 1997. Teory Organisasi: Suatu Pendekatan Makro. Jakarta: PT. Gramedia Pusat Utama.

M. Aziz Firdaus. 2012. Metode penelitian. Tangerang: Jelajah Nusantara.

Nachrowi, Usman H. 2005. Penggunaan Teknik ekonometrika., Jakarta; PT. Raja Grafindo Persada

Nazir, Muhammmad. 2002. Metode Penelitian. Cetakan Ketiga. Jakarta. : Ghalia Indonesia.

Saifuddin, Azwar. 2001. Reabilitas dan Validitas. Yogyakarta. Pustaka Pelajar. Siagian, Sondang P. 1995. 
Teori Pengembangan Organisasi. Jakarta: Bumi Aksara.

Simanjuntak, Tumpal M.S. 2001. Perbedaan antara Organisasi (Organization) dengan Kelembagaan. Jakarta: PT. Raja Grafindo Persada.

Sugiyono. 2005. Metode Penelitian. Bandung; Alfa Beta

Suhardiyono, L. 1992 Penyuluh : Petunjuk Bagi Penyuluh Pertanian. Penerbit Erlangga. Jakarta

Taneko, B. Sulaiman. 1993. Struktur dan Proses Sosial: Suatu Pengantar Sosiologi Pembangunan. Jakarta: PT. Raja Grafindo Persada.

Wiraatmadja, Soekandar. 1990. Pokok-pokok Penyuluh Pertanian (cetakan ke-14) CV Yasaguna. Jakarta. 